\title{
Derek Pletcher, First Course in Electrode Processes
}

\author{
2009, XIII + 297 p., 79.95 \$; ISBN: 978-1-85755-893-0
}

\author{
Rudolf Holze
}

Received: 3 January 2011 / Accepted: 3 January 2011 / Published online: 22 January 2011

(C) Springer-Verlag 2011

Hardly could an inspection copy have arrived at a more suitable time: The book turned up just a few days before the reviewer started a lab course combining theory and application of electrochemical methods in organic synthesis. Because electrochemistry apparently is not a natural topic in bachelor (and even master) courses any more a textbook suitable at this level and prepared in a way easily accessible for readers with only some limited background in Physical Chemistry is highly welcome. This book named aptly "A First Course in Electrode Processes" is offered in a second edition-almost a guarantee of a work well done already at first try. On closer inspection, it turns out that title and content agree: there is not much about thermodynamic aspects of electrochemistry except for some simple considerations of cell voltages and Gibbs energy. Thus, the present book will presumably not be a complete text for bachelor courses - whether they start in the most traditional fashion with "electrolytics" (as named by Bockris and Khan years ago) and the Born-Haber cycle in a certainly justified attempt to explain the dissolution of a solid crystal of, e.g., rock salt in water or discuss concentration effects and Walden rule in electrolytic conductance. The book is more of a second part-without telling the reader where to look for the first part. Admittedly-beyond the observation of

R. Holze $(\bowtie)$

Technische Universität Chemnitz, Institut für Chemie,

Straße der Nationen 62,

09111 Chemnitz, Germany

e-mail: Rudolf.holze@chemie.tu-chemnitz.de dissolution and solvation - things in electrochemistry of solutions tend to be somewhat dry, but to do completely without it is somewhat risky - this is certainly a practical limitation of this book. And apparently, this aspect has escaped the back cover artist: There it is frankly claimed, that the present book provides a basis for an introductory course on electrochemistry. Well- sort of half a basis. And even this is not exactly the truth because selection of topics appears to be based on a rather personal view. No other reason comes into mind after searching without result for corrosion-applied electrochemistry with certainly a quite substantial scientific, technological, and economic importance - or spectroelectrochemistry.

The book is generously illustrated, and only in some details of axis labeling the author seems to be a fan of some old fashions (providing a somewhat dated example in a textbook for students). A final chapter provides problems enabling the interested student to find out whether he or she has digested the offered selection of topics and aspects successfully. Answers are provided just a few pages later. The book is a nice and helpful addition to every library associated with a place where master courses in experimental electrochemistry are offered; it will support every lecture dealing with experimental and applied electrochemistry. Its rather steep price will most likely keep it away from the students' bookshelf.

Rudolf Holze

Chemnitz 